\title{
La fotografía digital como una estética sociotécnica: el caso de la Iphoneografía
}

\section{Digital Photography As Sociotechnical Aesthetics: The Case Of The Iphoneography}

\author{
Edgar Gómez Cruz \\ Universidad de Leeds, Inglaterra \\ E.Gomez@leeds.ac.uk
}

- Resumen - Se presenta el esbozo de una agenda de investigación que se erige como continuación de un proyecto de redefinición de la fotografía, desde la ciencia social, como un objeto de estudio más allá de su carácter representacional o semiótico. La propuesta se fundamenta en los hallazgos de un estudio sobre prácticas fotográficas que utilizó el método etnográfico. En la primera parte se plantea el marco teórico, problematizando a la fotografía como representación y reformulándola desde su materialidad, uso y tecnologías, para definirla como una red sociotécnica que se visibiliza en prácticas. La segunda parte describe la relación entre la fotografía y el establecimiento de una propuesta estética a través de las prácticas que la constituyen, para después centrarse en Iphoneografía. Finalmente, se establecen cuestionamientos.

Palabras clave: fotografía, Iphoneografía, representación, fotografía y sociedad, redes sociales.

Abstract - The following paper presents the beginning of a research agenda that emerges as a project of redefining photography, from Social Sciences, as an object of study beyond its representational or semiotic character. The purpose of this text, then, extends and builds on the result of the study of photographic practices using ethnographic methodology. This article is divided into three parts: First, the article presents the theoretical framework used to develop our approach to photography, which question photography as representation, and reformulates its materiality, its uses and technologies so as to define photography as a socio-technical network which appears in certain practices. The second part describes the relationship between photography and the establishment of an aesthetic proposal through its constituent practices, so as to focus on Iphoneography. Finally, the third part organizes a series of future questions, rather than conclusions, proposed as the beginning of the mentioned start of our research agenda.

Keywords: Photography, Iphoneography, Sociotécnica, Photography and Society, Social Networks. 


\section{LA FOTOGRAFÍA MÁS ALLÁ DE LA REPRESENTACIÓN}

La gran mayoría de los trabajos que existen sobre fotografía centran su discusión en el análisis de la imagen como representación, es decir, en su mensaje o significado. Este texto se sitúa, por el contrario, dentro de un análisis sociológico sobre la agencia fotográfica en la vida cotidiana, una cuestión teórica todavía pendiente (de Miguel y Ponce de León), y especialmente sobre la fotografía digital. De esta manera, el presente texto busca tender un puente entre los estudios de comunicación y culturales, la sociología del arte y los estudios sociales de tecnología, utilizando una herramienta que resulta de utilidad: la teoría de las prácticas.

Se propone, entonces, extender la idea de la imagen como texto a una idea de la imagen como materialización de una parte de la agencia fotográfica, que no se reduce a la fotografía ni se centra necesariamente en ella. Es decir, estudiar a la fotografía como práctica de acción y no como un «índice», «mime» o «lenguaje». Esta idea no es nueva y parece haber una corriente en los estudios de los medios que vira justamente hacia esta posición. Por ejemplo, Couldry propone un nuevo paradigma que no «se centre directamente sobre el texto mediático o la producción económica de los medios» (116) sino que «trate a los medios como un conjunto abierto de prácticas, relacionadas a, u orientadas alrededor de, los medios» (117); paradigma que ha ido consolidándose en los estudios sobre medios y «nuevos medios» (Bräuchler y Postill). En ese sentido, el estudio de la fotografía, aun con sus propias características, puede entenderse desde estas aproximaciones en tanto que producto cultural.

Aunque la relación entre el objeto fotográfico y la mirada como proceso de construcción simbólica sigue estando vigente como una preocupación importante, los cambios en la práctica fotográfica, con la tecnología digital, generan nuevas relaciones con la materialidad de la imagen, las redes en las que se inserta y los nuevos usos que se hacen de ella. Esta propuesta teórica se sitúa en el vértice de tres aproximaciones: los estudios antropológicos sobre la fotografía, los estudios de ciencia y tecnología y la teoría de las prácticas.

Elizabeth Edwards, en un pequeño pero conciso texto titulado Las prácticas sociales como una teoría de la fotografía, reflexiona sobre los estudios antropológicos sobre fotografía en los últimos tiempos. Esta autora señala que:

Han empezado a surgir nuevas perspectivas teóricas sobre la fotografía que la definen, ya no como una esencia abstracta, sino como una práctica que puede ser entendida a través de cuestiones vinculadas con las relaciones entre las personas y las cosas, entendidas estas como mutuamente constitutivas de la experiencia y la praxis social (101).

Los trabajos que utilizan esta perspectiva, continúa Edwards, no buscan sustituir:

[...] las preocupaciones teóricas y ontológicas como la deixis y el rastro, o como las cualidades significantes de las imágenes, pero sí que complican y extienden las formas 
en que podemos pensar sobre las fotos y, de una forma crucial, los modos en que se produce la intersección entre dichas ideas y lo social, lo cultural y lo material (101).

Este enfoque da un giro hacia el entendimiento de la fotografía desde su materialidad y fenomenología, y "privilegia analíticamente lo experiencial por encima de lo semiótico» (104).

De esta manera, la aproximación al estudio de la fotografía aporta tres elementos clave para problematizar a la fotografía como representación: la reflexión de la fotografía en contextos de uso y producción, atender a la materialidad de las imágenes y una «mirada de extrañamiento» ante la práctica fotográfica, tan cotidiana y común.

Una propuesta distinta, pero complementaria a la anterior, es la elaborada por el filósofo Patrick Maynard. Según este autor, no se puede entender a las fotografías como representaciones sin entender, primero, a la fotografía como tecnología; cuestión parecida a la planteada por Lister cuando dice que:

La manera de pensar la naturaleza de la fotografía a través de las fotos y la prioridad concedida a la fotografía como imagen y signo por encima de la fotografía como tecnología [...] se hace eco de un prejuicio mucho más extendido, un punto débil en el seno de las humanidades -en realidad, en el seno de los estudios de las formas culturales y de los medios de todo tipo. Nos referimos a la subestimación del papel de la tecnología en las historias y las teorías del arte, de los medios de comunicación y de la fotografía (235).

Maynard lleva este argumento al extremo al estudiar a la fotografía como una más de una serie de foto-tecnologías:

La fotografía es un conjunto de tecnologías para usar luz y radiaciones similares, para hacer imágenes físicas, permanentes o transitorias en superficies receptoras (químicas o electrónicas), mediante emisores y moduladores de la radiación. La modulación incluye refracción, difracción, reflexión, transmisión, bloqueo, filtraje y como operaciones ópticas. Los receptores son superficies físicas, marcadas ya sea permanente o transitoriamente como pantallas de receptoras (98).

En su texto The Engine of Visualization, ahonda y explica a fondo su propuesta. Para Maynard, y lo recuerda continuamente, la fotografía es una tecnología y, como toda tecnología, sirve para "amplificar nuestros poderes de hacer cosas» (15). La fotografía, señala, amplifica dos poderes en particular: el poder de imaginar cosas y el poder de detectar cosas. La clave es que la fotografía, como muchas otras herramientas, puede hacer que varias de sus posibilidades interactúen unas con otras simultáneamente de formas útiles. Partiendo de este punto de vista, desarrolla el proyecto de entender a la fotografía como una tecnología que, para evolucionar, no solo ha dependido de sus usos sociales, sino que se ha nutrido de diversas innovaciones tecnológicas. Según Maynard, se debe estudiar a la fotografía como se estudiaría un molino de viento. La fotografía, de este modo, es solo una de las muchas posibles foto-tecnologías. Para el autor, las foto-tecnologías son tecnologías 
capaces de detectar la presencia de luz y, en algunas ocasiones, como es el caso de la fotografía, marcar la presencia de esta luz sobre alguna superficie. Sin embargo, la fotografía tiene una capacidad extra: no solo detecta la luz y marca su presencia sobre una superficie, sino que esa combinación puede «describir» y «representar» aquello que genera las perturbaciones en la recepción de la luz. De esta forma se combina con otro de nuestros poderes: el poder de imaginar.

\section{LA FOTOGRAFÍA COMO RED SOCIOTÉCNICA}

Una red sociotécnica podría definirse como un ensamblaje de componentes materiales y no materiales, discursivos, tecnológicos y sociales que dota de sentido y se configura a través de prácticas (Bijker, Hughes y Pinch). El entendimiento de la fotografía como red sociotécnica se sitúa en el vértice de varias aproximaciones teóricas, donde la clave común, y que resulta fundamental de expresar aquí, es la renuncia explícita a las explicaciones deterministas, ya sean tecnológicas o sociales:

Lo técnico está construido socialmente, tanto como lo social está construido técnicamente. Todos los ensamblajes se mantienen unidos tanto por lo técnico como por lo social: [...] lo sociotécnico no debe ser tratado simplemente como una combinación de factores sociales y técnicos. Es algo sui generis. En lugar de artefactos, nuestra nueva unidad de análisis es ahora el «ensamblaje sociotécnico». [...] La sociedad no está determinada por la tecnología, ni la tecnología está determinada por la sociedad. Las dos emergen como dos caras de una misma moneda sociotécnica durante el proceso de construcción de los artefactos, los hechos y los grupos sociales relevantes (Bijker 273-4).

De esta forma, sigo la propuesta de Larsen, un autor que ha elaborado estudios sobre fotografía digital, quien plantea que: «La fotografía digital es una red tecnológica compleja en construcción en lugar una sola tecnología fijada» (142). La «novedad» de la fotografía digital, continúa, relaciona por un lado: «la digitalización de las imágenes, la convergencia de los medios y las nuevas actuaciones de la socialidad (relacionadas con cambios sociales más amplios que se dan a través de redes de socialidad a distancia en tiempo real y colaborativas)» (143). De esta forma, Larsen amplía el contexto mediante el cual se entiende a la fotografía digital, introduciendo como concepto teórico clave para su estudio el de la tecnología. El autor entiende a la fotografía como una red compleja que genera una agencia compartida:

Las tecnologías son híbridos. Desde esta posición la fotografía es tan evidentemente material y social, objetiva y subjetiva, es decir, heterogénea. Es una compleja amalgama de tecnología, discurso y prácticas. La agencia fotográfica es un efecto relacional que se da cuando una red heterogénea de humanos y no humanos toma lugar (145).

Con esta perspectiva, también se evita caer en posibles determinismos ya que nunca hay un elemento que determine directamente a otro, sino que se trata de un proceso en constante evolución e interarticulación. Si bien se hace énfasis en la fotografía como una serie de tecnologías, lo que se propone aquí no es elaborar un 
estudio sobre su desarrollo técnico sino sobre las redes sociotécnicas que se materializan en prácticas de fotografía digital y, al mismo tiempo, cómo estas prácticas de fotografía digital consolidan y estructuran redes sociotécnicas más amplias y, en última instancia, el significado de lo que es fotografía.

\section{LA FOTOGRAFÍA COMO PRÁCTICA}

El concepto de prácticas resulta útil para entender tanto la formación de una red sociotécnica como la forma en la que esta evoluciona. Schatzki, en la introducción al libro que coeditó, propone situar a las prácticas como «el fenómeno social fundamental» (11), el objeto de estudio de los estudios sociales, y, aunque el autor reconoce que no existe una «teoría de las prácticas» unificada y clara, sino que se trata más de una familia de concepciones, lo que tienen en común todas ellas, en su opinión, es que «las prácticas son el lugar donde el entendimiento se estructura y se hace inteligible» (12). Por ello, «Mediante los entendimientos e inteligibilidades que portan, las prácticas son el dominio donde la mentalidad / actividad de la sociabilidad y el individuo se organizan y enlazan» (13). Es decir, en lugar de explicar los «hechos sociales» o la creación de sentido mediante la interacción, la orientación de las prácticas no analiza «entidades ontológicas, procesos fundacionales, partes de la sociedad, estructuras sociales, sistemas culturales, mecanismos de comportamiento o facultades cognitivas», sino que entiende que estos son «logros situados por parte de las partes cuyas prácticas locales ‘ensamblan' las escenas recurrentes de acción que forman una sociedad estable» (140). En ese sentido, y trasladando la propuesta al estudio de la fotografía, los «usos sociales» de la fotografía serían precisamente las consolidaciones de determinadas prácticas continuadas en el tiempo, lo que daría como resultado la «significación social» de la fotografía.

En un texto que contextualiza e introduce la teoría de las prácticas en el conjunto de la teoría social, Reckwitz define las prácticas como:

Una forma rutinizada en la que los cuerpos son movidos, los objetos manejados, los sujetos tratados, las cosas descritas y el mundo es entendido. El decir que las prácticas son «practicas sociales» es de hecho tautológico: una práctica es social como lo es el «tipo» de comportamiento y entendimiento que aparece en diferentes localidades y diferentes puntos del tiempo y que es portado por diferentes cuerpos/mentes (250).

La relevancia de esta aproximación hace que se discuta un «viraje hacia las prácticas» en las ciencias sociales (cfr. Schatzki, Knorr-Cetina y Von Savigny). La adopción de una teoría de las prácticas, desde un punto de vista sociológico, tiene varios méritos ya que:

No depende de las presunciones de las elecciones individuales, ni de las de actos racionales o de la expresión de la identidad personal. Las teorías de prácticas también comprenden nociones de conducta no instrumentalistas, enfatizando el rol de la rutina por un lado, y de la emoción, la corporalización y el deseo en el otro (Warde 16). 
La aproximación del estudio de las prácticas resulta útil para integrar, como un todo indivisible, las tecnologías y sus usos: «Para la teoría de las prácticas, los objetos son necesariamente componentes de muchas prácticas -tanto como actividades corporales y mentales indispensables» (Reckwitz 252). Por lo que hay un creciente número de trabajos, desde la teoría de las prácticas, que tratan específicamente el tema de la fotografía (Larsen; Tinkler; Shove \& Pantzar). En resumen, las prácticas fotográficas incluyen todas aquellas rutinas de preparación, producción, uso y socialización de las imágenes fotográficas, así como el significado que para determinado grupo tienen. Es decir, de lo que se trata es de estudiar las prácticas, tanto de producción como de uso de las imágenes, así como la forma en la que las personas se suman a una determinada práctica y cómo la integran en su vida cotidiana.

\section{REDES SOCIOTÉCNICAS Y ESTÉTICAS FOTOGRÁFICAS}

En un texto anterior (Gómez Cruz y Meyer), se planteaba que la fotografía, como red sociotécnica, ha estado siempre en una temporalidad pendular. En dicho texto se proponía delimitar estas temporalidades en cinco fases distintas, cada una de las cuales representaba una relación específica entre las prácticas de producción de imágenes, las tecnologías utilizadas para ello, los discursos sobre dichas prácticas y las estéticas dominantes. Si bien estas etapas son más un ejercicio cuya delimitación parece forzada y problemática, el objetivo no es construir una historia de la fotografía, sino evidenciar los elementos claves en distintos momentos de dicha historia que es más fluida y compleja que lo que aquí se propone.

En la primera etapa, la pionera a partir de la invención de la fotografía, esta se establecía como un avance científico para la reproducción fidedigna de la realidad. Fontcuberta apunta que «lo que conocemos comúnmente como fotografía solo cristaliza a principios del siglo XIX porque es justamente en ese momento cuando la cultura tecnocientífica del positivismo requería un procedimiento que certifique la observación empírica de la naturaleza» (61). Las características de las tecnologías utilizadas para la creación de imágenes, especialmente cambiantes en esta etapa, eran por demás sofisticadas. Se requería de conocimientos precisos, de equipos grandes y pesados y la estética fotográfica tenía limitaciones obvias de tiempos y formas. Por citar un ejemplo: el tortuoso tiempo que se requería para hacer un retrato debido a la sensibilidad de los químicos. De esta manera, es sobre todo el paisajismo el que sobresale en esta primera etapa.

La segunda etapa se inicia cuando George Eastman introduce la cámara Kodak, a principios del siglo xx y con ello se genera un mercado masivo para la fotografía, que hasta ese momento estaba reservada para amateurs, entusiastas, viajeros y profesionales cualificados. La fotografía, que solía necesitar de una «habilidad técnica» (y que por lo tanto, en el contexto histórico era mayoritariamente masculina, altamente especializada y orientada por la clase social), alcanzó a distintos grupos y comenzó a crearse un «público» masivo para la fotografía, incrementándose exponencialmente 
el número de personas que hacían fotografías (Oliver; Jenkins; Coe y Gates). De esta forma, empezaba a tomar forma el mercado de la fotografía: «el mercado amateur fue explorado, extraído y construido a partir de grupos sociales heterogéneos que no existían como tales antes de Eastman. Los nuevos amateurs y la cámara Eastman se co-produjeron entre sí» (Latour 117). Esta situación trajo como consecuencia la creación de nuevas formas de expresión visual, por ejemplo las llamadas «snapshots», es decir, imagines «casuales» y "hechas en casa» cuya única pretensión era generar recuerdos de momentos buenos y felices dentro del ámbito familiar (Chalfen; Hirsch y Rose). Es en esta segunda etapa que comienzan a establecerse ciertas divisiones que durante muchos años sustentaron el entendimiento social de la fotografía (y la estética fotográfica): la separación entre amateurs y profesionales, fotografía artística y casera, el fotoperiodismo como una rama específica del periodismo, etc.

En la tercera etapa, una que podríamos denominar de estabilización, la fotografía alcanzó prácticamente a todo el mundo y tomaron forma los campos específicos de la fotografía. Se consolidaron circuitos delimitados y cánones, tanto visuales como formales, en la creación fotográfica de las divisiones antes mencionadas. La fotografía artística tenía sus galerías, revistas especializadas, libros, curadores y profesionales que la validaban como tal. Los amateurs se erigían como un grupo conocedor de la técnica pero sin acceso a los códigos de la elite fotográfica y que se organizaban en «clubes de cámaras» (Schwartz). Para la fotografía casera, se estableció lo que Chalfen denominó: "Cultura Kodak». Sarvas y Frohlich señalan que el Modelo Kodak se componía de tres elementos: «La tecnología (rollos de película y una cámara simple), un modelo de negocio (vender carretes y un servicio de revelado e impresión), y una práctica (capturar imágenes de los miembros de la familia y los eventos familiares)» (16). Dichos elementos «establecieron una Cultura Kodak en el siglo xx y siguieron siendo la forma dominante de la fotografía por casi un siglo» (16). En la Cultura Kodak, solo era fotografiable aquello que se quería hacer perdurar en la memoria: ocasiones especiales, momentos únicos, personas determinadas. Por ello, Bourdieu reflexionaba sobre lo que los campesinos de Lesquire consideraban digno de fotografiarse: «no se fotografía lo que se tiene enfrente todos los días», decían al mostrárseles una fotografía artística en donde aparecía la hoja de un árbol (72). De esta manera, en la vida cotidiana, este acercamiento a la fotografía, casi desde un punto de vista ritualístico, hacía que las imágenes fotográficas funcionaran como objetos simbólico-culturales para la cohesión de un grupo social como la familia, los amigos cercanos o los compañeros de trabajo. Bourdieu se refiere a la «función familiar» de la fotografía como aquella que busca: «solemnizar y eternizar los grandes momentos de la vida familiar, y reforzar, en suma, la integración del grupo reafirmando el sentimiento que tiene de sí mismo y de su unidad» (57). Cuestión también documentada por otros autores como Chalfen o Slater.

La cuarta etapa comienza a tomar forma con la emergencia de las cámaras digitales; nuevos actores empresariales aparecen y se consolidan mientras que Kodak, 
después de casi un siglo de ser casi sinónimo de fotografía, se va a la bancarrota. Los límites institucionales de la fotografía comienzan a desdibujarse y se generan circuitos híbridos donde confluyen fotógrafos profesionales, amateurs, fotoperiodistas y fotografías caseras (por ejemplo, Flickr o Facebook). Pero, sobre todo, lo que sucede es un regreso al control que, en la primera etapa, los fotógrafos y fotógrafas tenían sobre el proceso completo de producción de imágenes. Así, ciertos usos como el autorretrato (Ardèvol y Gómez Cruz) o la distribución de imágenes sexuales en plataformas de libre acceso, desestabilizan también conceptos sociales más amplios como público y privado (Lasén y Gómez Cruz).

\section{LA IPHONEOGRAFÍA COMO RED SOCIOTÉCNICA}

La quinta fase, propuesta por Gómez Cruz y Meyer, llega con la incorporación de las cámaras en los teléfonos celulares. Por un lado, la cámara fotográfica deja de ser el instrumento básico para la captura de imágenes, por otro, se combinan dos instrumentos muy poderosos pero hasta entonces separados: un dispositivo de captura de imágenes y un dispositivo de comunicación. De esta forma, no solo la producción y procesamiento, sino también la difusión y exhibición, podían hacerse desde el mismo aparato. Así, la inmediatez, la conectividad y la capacidad de tomar, borrar, elegir y enviar, casi en tiempo real, una fotografía, generaron prácticas que cambiaron el objeto de lo fotográfico (Okabe e Ito) y crearon «identidades fotográficas» nuevas como los fotobloggers (Cohen). Ahora bien, el primer dispositivo que logró, mediante su identidad corporativa y su modelo de negocio (las apps), convertir al teléfono celular en un dispositivo fundamentalmente de creación de imágenes móviles y «sociales» fue el Iphone. La página de intercambio y exhibición de fotografías flickr.com, que en su momento fue la más importante por número de usuarios y dinámicas, lleva un par de años mostrando la cámara más usada para tomar fotografías: el Iphone. De esta forma, no resulta casual que, en la presentación de la actualización del Iphone 4, Steve Jobs haya presentado al teléfono como «una preciosa leica vieja».

La creación de una red sociotécnica de fotografía relacionada exclusivamente con un dispositivo se debió no solo a las potentes aplicaciones que surgieron para el procesamiento de imágenes, sino a la conjunción de estas aplicaciones con una conectividad constante (el Iphone fue el primer dispositivo cuyo contrato de permanencia exigía una conexión de datos). Así, surgieron coyunturas sociotécnicas que posibilitaron el éxito de aplicaciones como Instagram, recientemente adquirida por Facebook por mil millones de dólares, y quizá el paradigma de la fotografía móvil por su combinación de dos elementos claves: estética(s) preconstruida(s) y la posibilidad de compartir instantáneamente. Como se mencionó anteriormente, el campo fotográfico parece haberse desestabilizado, complejizándose dicotomías como amateur / profesional (Gómez Cruz, Profesionales y amateurs). Precisamente una de las arenas donde estas luchas simbólicas se gestan es en el uso de la fotografía móvil como un movimiento artístico. 
Mientras que existen claras controversias, lo cierto es que una gran cantidad de personas, tanto profesionales como amateurs, han adoptado, especialmente el Iphone como marca, como un instrumento clave en la producción de imágenes y discursos sobre esas imágenes. Así, aparecen blogs especializados, circuitos propios y, sobre todo, los circuitos tradicionales de la fotografía como galerías y revistas especializadas, utilizan el concepto para referirse a un tipo de movimiento artístico híbrido que se compone tanto de profesionales como de amateurs y que parece tener elementos particulares de entre los cuales vale la pena destacar dos: por un lado el uso de aplicaciones (apps), y por otro el componente de intercambio y exhibición implícito en el concepto mismo. Cuestiones que se detallarán a continuación.

\section{LAS APPS COMO UNA ESTÉTICA PRECONSTRUIDA}

Manovich apunta que los pioneros de la computación, que diseñaron los sistemas sobre los que hoy se sustentan los programas de edición de imágenes, video, lenguajes de programación, etc., «son importantes artistas de nuestro tiempo. Quizá los únicos artistas que son realmente importantes y que serán recordados de este periodo histórico» (22). Continúa diciendo:

Es momento de que tratemos a las personas que han articulado ideas fundamentales sobre la interacción entre humanos y computadoras como los mayores artistas modernos. No solo ellos inventaron nuevas formas de representar cualquier dato (y por lo tanto, por default, todos los datos que tengan que ver con "cultura») sino que han radicalmente redefinido nuestras interacciones con todos los datos de la vieja cultura. (23)

Más allá de la grandilocuencia de su postura, Manovich plantea una cuestión que parece clave, la estrecha relación entre el código computacional y la integración de una serie de saberes en él. Hablando específicamente de la fotografía, los dispositivos de captura de imágenes digitales integran, tanto en su diseño como en sus posibilidades, cada vez más operaciones que solían efectuarse anteriormente como un conjunto de saberes / herramientas y que ahora convergen en el diseño de programas informáticos que se incluyen, cada vez más, en las cámaras. Por poner dos ejemplos que parecen transversales a todas las cámaras digitales: el cambio de ISO y el blanco y negro. Anteriormente, los fotógrafos profesionales solían cargar con películas de sensibilidad fotográfica distinta dependiendo de los requerimientos particulares de cada toma. También era común ver fotógrafos con dos o más cámaras que normalmente tenían películas distintas, ya sea color y blanco y negro, una con un ISO elevado y otro menor, o una con diapositivas y otra con carretes de 35 $\mathrm{mm}$. En las cámaras digitales todas estas variantes se incorporan como funciones computacionales. Casi en cualquier cámara se puede escoger la sensibilidad de luz (el ISO) o si la toma es en blanco y negro o color. 
Estos son solo dos ejemplos de cómo, en la fotografía digital, los códigos computacionales han reemplazado operaciones que requerían materiales o procesos distintos (Gómez Cruz y Meyer). Como apuntan Rubinstein y Sluis: «Al eliminar discretamente las referencias al conocimiento especializado y artesanal gracias al software de fotografía digital, la fotografía se incorpora en el grupo de las amistosas aplicaciones multimedia diseñadas para gustar a cada usuario de computadora» (15). Hay además un elemento extra que cada día gana mayor importancia y que se relaciona con las técnicas de postprocesamiento de imágenes. Durante varios años, el procesamiento de imágenes digitales se hacía mediante programas informáticos como el Photoshop, que requerían para su uso una serie de conocimientos especializados. Sin embargo, la fotografía móvil (y cada vez más la hecha por cámaras digitales) integra esos saberes y herramientas informáticas, uniéndolos en forma de pequeños paquetes llamadas «aplicaciones» $\mathrm{o}$ «apps» que se utilizan con frecuencia en la práctica fotográfica. Estas aplicaciones integran, en forma de filtros, procesos y opciones, elementos que emulan la combinación de técnicas, tecnologías, materiales y conocimientos para dar ciertos resultados: viñeteado, filtros de color, alto contraste, saturación, crossprocess, fotografías estilo polaroid y un largo etcétera, se añaden a la imagen como opciones automáticas de postprocesamiento (muchas veces en tiempo real, al momento de tomar la fotografía). De esta manera, una cierta estética, conseguida previamente como el resultado de la mezcla entre unos saberes y unas herramientas determinados, aparece al alcance de cualquiera en forma de menú de opciones predefinidas. De esta manera, la materialidad, temporalidad y aprendizaje fotográfico se transforman en una mera selección de posibilidades preconstruidas que se afinan y adquieren mediante un proceso vicario y de ensayo y error. Pero, sobre todo, a partir de la experiencia social de la fotografía.

\section{LA FOTOGRAFÍA «SOCIAL»}

El último elemento a reseñar tiene relación con el carácter «social» de la fotografía. El hecho de que las imágenes puedan compartirse con tanta facilidad genera nuevas formas de relación con la fotografía, por ejemplo, modificándose su trayectoria temporal de uso. Mientras que las imágenes analógicas parecían servir como un recordatorio estático de una situación pasada, es decir, eran un objeto para la memoria. En el caso de la imagen digital, su temporalidad de uso también resulta más inmediata y, en algunos casos, perecedera casi instantáneamente (por ejemplo, cuando se utiliza una imagen para mostrar el lugar en el que se encuentra determinada persona en determinado momento, imagen que pierde su sentido una vez que la persona ya no se encuentra ahí y es eliminada). Este "presente continuo» de la imagen, que funciona como conexión inmediata entre personas, lugares y situaciones, en muchas ocasiones pierde su carácter de memoria temporal y funciona únicamente como conexión. De 
esta forma, la imagen en red (Gómez Cruz, De la Cultura Kodak) adquiere sentido en la medida en que se inserta en contextos de socialidad cotidianos, no solo en los momentos extraordinarios y no únicamente por lo que se representa, sino por el significado que se le dota al mismo acto de fotografiar que cada vez está más estrechamente relacionado con el uso de dichas imágenes en plataformas de redes sociales (como Facebook o Instagram). De esta forma, la imagen adquiere nuevos significados en relación a las redes en las que se inserta. No es lo mismo una fotografía en un álbum, en Facebook o en Flickr; no es igual un correo electrónico con una imagen anexada que un correo con el enlace a una fotografía en Internet, etc. La imagen se vuelve código y se inserta en otros códigos más amplios adaptándose a sus propias lógicas. La imagen se vuelve un interfaz, una conexión y, de alguna forma, un lenguaje, con una «estética sociotécnica».

\section{HACIA UNA AGENDA DE INVESTIGACIÓN}

Como se ha detallado, se ha propuesto en este texto entender a la fotografía como algo más que una representación, centrando su análisis en los discursos, tecnologías, usos, en pocas palabras, en sus prácticas, no solo las de la producción de la imagen sino también las de postproducción, exhibición y distribución. Proyecto que busca recorrer el camino contrario al planteado por Barthes, quien decía enfáticamente no estar interesado en la sociología de la fotografía sino en su esencia. En este caso se retoma la idea de Bourdieu, quien apuntaba que su interés estaba puesto en la fotografía como "práctica social generalizada» (23) ya que, como nos recuerda Sutton, las ontologías son a su vez ideas que se edifican como artefactos, que «definen» las funciones que se esperan de la fotografía.

Siguiendo entonces un análisis sobre las distintas redes sociotécnicas mediante las que se construía nuestro entendimiento de la fotografía, se propuso que, a partir de la emergencia de las cámaras digitales y especialmente desde la incorporación de un dispositivo de captura de imágenes en los teléfonos móviles, se está generando una transformación sustancial en el campo de la fotografía, tanto en su política como en su estética. Aún es pronto para apresurar una conclusión, especialmente porque los desarrollos tecnológicos siguen sucediéndose y porque el campo de luchas simbólicas para definir los nuevos límites, códigos y estéticas de la fotografía, sigue abierto. Lo que se propuso aquí es el inicio de una agenda de investigación que buscará describir dichos cambios en una cultura digital cada vez más claramente identificable.

\section{REFERENCIAS}

Ardèvol, Elisenda y Edgar Gómez Cruz. «Cuerpo privado, imagen pública: el autorretrato en la práctica de la fotografía digital». Revista de Dialectología y Tradiciones Populares. Medio impreso. 
Bassett, Caroline. "Cultural Studies and New Media». New Cultural Studies: Adventures in Theory. Eds. Gary Hall \& Clare Birchall. Georgia: University of Georgia Press, 2007. 220-4. Medio impreso.

Bijker, Wieber. Of bicycles, bakelites, and bulbs: Toward a theory of sociotechnical change. Cambridge: MIT Press, 1995. Medio impreso.

Bijker, Wieber, Thomas Hughes y Trevor Pinch. The Social Construction of Technological Systems: New Directions in the Sociology and History of Technology. Cambridge: MIT Press, 1989. Medio impreso.

Bourdieu, Pierre. Un arte medio: ensayo sobre los usos sociales de la fotografía. Barcelona: Gustavo Gili, 2003. Medio impreso.

Bräuchler, Bridget y John Postill. Theorising Media and Practice. Oxford and Nueva York: Berghahn, 2010. Medio impreso.

Chalfen, Richard. Snapshot Versions of Life: Ohio: Bowling Green State University Popular Press, 1987. Medio impreso.

Coe, Brian y Paul Gates. The Snapshot Photograph: The Rise of Popular Photography. Londres: Ash \& Grant, 1977. Medio impreso.

Cohen, Kris. «What Does the Photoblog Want?». Media, Culture \& Society 27, 6 (2005). 883-901. Medio impreso.

Couldry, Nick. «Theorising Media as Practice». Social Semiotics 14, 2 (2004). 115-32. Medio impreso.

de Miguel, Jesús y Omar Ponce de León. «Para una sociología de la fotografía». Reis 84 (1998). 83-124. Medio impreso.

Edwards, Elizabeth. «Las prácticas sociales como una teoría de la fotografía». Instantáneas de la teoría de la fotografía. Ed. Pedro Vicente. Tarragona: Arola Editors, 2009. 101-12. Medio impreso.

Fontcuberta, Joan. La cámara de Pandora. La fotografi@ después de la fotografía. Barcelona: Gustavo Gili, 2010. Medio impreso.

Gómez Cruz, Edgar y Eric Meyer. «Creation and Control in the Photographic Process: Iphones and the Emerging Fifth Moment of Photography». Photographies 5, 2 (2012). 203-21. Medio impreso.

Gómez Cruz, Edgar. «Profesionales y amateurs en la cultura digital. Notas empíricas sobre las prácticas de fotografía digital». Pensar la comunicación. Reflexiones resultados de investigación. Medellín: Universidad de Medellín, 2010. Medio impreso.

Gómez Cruz, Edgar. De la cultura Kodak a la imagen en red. Una etnografía sobre fotografía digital. Barcelona: Editorial UOC, 2012. Medio impreso.

Hirsch, Marianne. Family Frames: Photography, Narrative, and Postmemory. Cambridge: Harvard University Press, 1997. Medio impreso.

Jenkins, R. V. «Technology and the Market: George Eastman and the Origins of Mass Amateur Photography». Technology and Culture 16 (1975). 1-19. Medio impreso. Larsen, Jonas. «Practices and Flows of Digital Photography: An Ethnographic Framework». Mobilities 3, 1 (2008). 141-60. Medio impreso. 
Larsen, Jonas. «Families Seen Sightseeing: Performativity of Tourist Photography». Space and Culture 8 (2005). 416-34. Medio impreso.

Latour, Bruno. «Technology Is Society Made Durable». A Sociology of Monsters: Essays on Power, Technology and Domination. Ed. John Law. Routledge: Londres, 1991. 103-31. Medio impreso.

Lister, Martin. «¿Olvidar la tecnología?». Instantáneas de la teoría de la fotografía. Ed. Pedro Vicente. Tarragona: Arola Editors, 2009, 227-42. Medio impreso.

Manovich, Lev. «New Media from Borges to Html». The New Media Reader. Ed. Noah Wardrip-Fruin y Nick Montfort. Cambridge, Mass.: MIT Press, 2003. 13-25. Medio impreso.

Marien, Mary W. Photography: A Cultural History. Londres: Laurence King Publishing, 2002. Medio impreso.

Maynard, Patrick. «Photography». A Companion to Aesthetics: The Blackwell Companion to Philosophy. Ed. Stephen Davies, Kathleen Marie Higgins, Robert Hopkins, Robert Stecker and David E. Cooper. Oxford: Blackwell, 2009. 98-101. Medio impreso.

Maynard, Patrick. The Engine of Visualization: Thinking through Photography. Nueva York: Cornell Universtiy Press, 2000. Medio impreso.

Olivier, Marc. «George Eastman's Modern Stone-Age Family: Snapshot Photography and the Brownie». Technology and Culture 48, 1 (2007). 1-19. Medio impreso.

Okabe, Daisuke y Mimi Ito. «Camera Phones Changing the Definition of Picture-Worthy». Japan Media Review 29 (2003). Medio impreso.

Reckwitz, Andreas. «Toward a Theory of Social Practices». European Journal of Sociology 5, no. 2 (2002). 243-63. Medio impreso.

Rose, Gillian. «'Everyone’s Cuddled up and It Just Looks Really Nice’: An Emotional Geography of Some Mums and Their Family Photos». Social \& Cultural Geography 5, 4 (2004). 549-64. Medio impreso.

Rubinstein, Daniel y Katrina Sluis. "A Life More Photographic». Photographies 1, 1 (2008). 9-28. Medio impreso.

Sarvas, Ristro y David Frohlich. From Snapshots to Social Media: The Changing Picture of Domestic Photography. Nueva York: Springer-Verlag, 2011. Medio impreso.

Schatzki, Theodore, Katherine Knorr-Cetina y Eike Von Savigny. The Practice Turn in Contemporary Theory. London: Routledge, 2001. Medio impreso.

Schatzki, Theodore. Social Practices: A Wittgensteinian Approach to Human Activity and the Social. Cambridge: Cambridge University Press, 1996. Medio impreso.

Schwartz, Donna. "Camera Clubs and Fine Art Photography: The Social Construction of an Elite Code». Journal of Contemporary Ethnography 15, 2 (1986). 165-95. Medio impreso.

Shove, Elizabet y Mika Pantzar. «Recruitment and Reproduction: The Careers and Carriers of Digital Photography and Floorball». Human Affairs 2 (2007). 154-67. Medio impreso. 
406

Slater, Don. «Marketing Mass Photography». Visual culture: the reader. Ed. Jessica Evans y Stuart Hall. Londres: Sange / Open University, 1999. Medio impreso.

Sutton, Damian. Photography, Cinema, Memory: The Crystal Image of Time. Minneapolis: University Of Minnesota Press, 2009. Medio impreso.

Tinkler, Penny. «A Fragmented Picture: Reflections on the Photographic Practices of Young People». Visual Studies 23, 3 (2008). 255-66. Medio impreso.

Tedlow, Richard. «The Beginning of Mass Marketing in America: George Eastman and Photography as a Case Study». Journal of Macromarketing 17, 2 (1997). 67-81. Medio impreso.

Warde, Alan. «Practice and Field: Revising Bourdieusian Concepts». Centre for Research on Innovation and Competition (CRIC), Universidad de Manchester. Fecha de ingreso 25 de agosto 2011. <http://www.cric.ac.uk/cric/Pdfs/DP65.pdf> Sitio web. 